\title{
Effect of Cyanobacteria (Nostoc species) Extracts on Osteogenesis Activities
}

\section{Phatthilakorn CHAMNANPUEN ${ }^{1}$, Veena SATITPATIPAN ${ }^{1}$, Sophon SIRISATTHA ${ }^{2}$ and Thanchanok MUANGMAN ${ }^{3, *}$}

\author{
${ }^{I}$ Department of Pharmacognosy, Faculty of Pharmacy, Mahidol University, Bangkok 10400, Thailand \\ ${ }^{2}$ Biodiversity Research Centre, Thailand Institute of Scientific and Technological Research, Tambon, \\ Pathum Thani 12120, Thailand \\ ${ }^{3}$ Expert Centre of Innovative Herbal Products, Thailand Institute of Scientific and Technological \\ Research, Pathum Thani 12120, Thailand
}

("Corresponding author's e-mail: thanchanok@tistr.or.th)

Received: 29 March 2018, Revised: 26 August 2018, Accepted: 30 September 2018

\begin{abstract}
This study focused on osteogenesis activities from Cyanobacteria (Nostoc species), including cytotoxicity, cell proliferation, cell differentiation and cell mineralization with osteoblast cell (MC3T3E1). The four Nostoc species; N. parmelioides, $N$ punctiforme, $N$. muscorum and $N$. paludosum were made axenic and cultured for a month. The ethanolic crude extracts were obtained by maceration extraction; the yield was in the range of $7.00-10.00 \%(w / w)$. By using the TLC technique, it was observed that in all of the samples, there were phytochemical bands corresponding with $\beta$-carotene and chlorophyll a which were used as standard compounds. As a result, all crude extracts had no toxic effect on osteoblast cells after being incubated for 24 and $48 \mathrm{~h}$ with various concentrations $(1-1,000 \mu \mathrm{g} / \mathrm{mL})$, although they did not significantly promote osteoblast proliferation. In addition, it was found that 3 crude extracts ( $N$. parmelioides, $N$ punctiforme, and $N$. paludosum) also promoted osteoblast differentiation significantly after being induced for 9 days. Similarly, there was no difference between the relative cellular mineralization among treatment groups after being induced for 25 days. The potential ethanolic extracts on osteoblast cell differentiation were further partitioned by liquid-liquid partition chromatography (hexane, dichloromethane and aqueous fractions), and were analyzed for osteoblast differentiation with alkaline phosphatase (ALP) activity. All of hexane and dichloromethane fractions from $N$. parmelioides $(181.72 \pm 6.75 \%$ and $195.11 \pm 3.27 \%), N$ punctiforme $(194.34 \pm 2.36 \%$ and $168.69 \pm 1.08 \%$ ), and $N$. paludosum $(191.54 \pm 7.66 \%$ and $167.12 \pm 9.46 \%$ ) had a significantly higher effect of ALP activity than their aqueous fractions. In conclusion, our data suggested that the nonpolar potential major compound, which might correspond with carotenoids ( $\beta$-carotene, xanthophyll and chlorophyll a) from Nostoc species, exhibited positive effects on osteoblast differentiation by increasing the alkaline phosphatase enzyme.
\end{abstract}

Keywords: Nostoc species, Cyanobacteria, Bone formation, Osteogenesis, Osteoblast differentiation

\section{Introduction}

Osteoporosis, a major public health problem, is one of the most common forms of metabolic bone disease, and involves low bone mass, resulting in an increased risk of fracture [1,2]. Osteoporosis results from an imbalance in bone remodeling relative to bone formation and bone resorption. There have been reports of bone formation decreasing as a function of increasing age, with bone reabsorption still being active at the same time. [3] It significantly affects life expectancy and quality of life in the aging human population [4]. Recently, several researchers reported that various phytochemical compounds, such as 
http://wjst.wu.ac.th

flavonoids, alkaloids, courmarins, stilbene, terprenoids, polyphenol, carotenoids and lignans, have promoted an effect on osteogenesis [5].

Nostoc is an edible microalga that belongs to the Nostocaceae group Cyanophyta, which forms spherical colonies that links together as filaments [6]. Traditionally, some species of Nostoc have been used in China as food sources or as a medicine to treat illness [7]. Moreover, Nostoc has also been used as a common dietary supplement in many countries; for example, Japan, Thailand, Philipines, Peru, Fiji, Ecuador, Java, Mongolia, Siberia, Mexico and Nordic countries. It has also been reported to have interesting biological activities such as anti-oxidant, anti-microbial, anti-bacterial, anti-fungal, cholinesterase inhibitory, a cytotoxic effect on cancer cells, and hypercholesterolemic effects [8]. It also has a wide range of bioactive compounds, which include carotenoids, phycocyanin, total phenols, tannin, alkaloids, flavonoids, and terpenoids similar to previous literature on phytochemical compounds [9-12]. However, studies on cyanobacteria especially in Nostoc species for the osteogenensis effect have been very limited. Therefore, the present study emphasized the effect of cyanobacteria (Nostoc species) extracts on osteogenesis activities, including cytotoxicity, cell proliferation, cell differentiation and cell mineralization.

\section{Materials and methods}

\section{Chemical reagents}

$\beta$-carotene, $\alpha$-tocopherol, genistein, xanthophyll, and chlorophyll a, $95 \%$ ethanol, dichloromethane, ethyl acetate, hexane, and methanol which are the analytical grade were purchased from Sigma Aldrich Co. (USA), WST-1 reagent (sigma, USA), an alkaline phosphatase, Diethanolamine Detection kit (Sigma Aldrich, USA), Pierce ${ }^{\circledR}$ BCA protein assay Kit. (Thermo Scientific, USA), Alizarine red S dye (Sigma Aldrich, USA) and cetylpyridinium chloride (Sigma Aldrich, USA).

\section{Cyanobacterial and growth conditions}

The unialgal Nostoc species were obtained from the Algal Expert Centre of Thailand Institute of Scientific and Technological Research. These included N. muscorum, N. parmelioides, $N$ punctiforme, and $N$. paludosum. All strains were made axenic organism and were grown at $27 \pm 2{ }^{\circ} \mathrm{C}$ with fluorescence light intensity of 1,500 - 2,000 lux in BG-11 medium (containing $\mathrm{NaNO}_{3}, \mathrm{~K}_{2} \mathrm{HPO}_{4} .3 \mathrm{H}_{2} \mathrm{O}, \mathrm{MgSO}_{4} .7 \mathrm{H}_{2} \mathrm{O}$, $\mathrm{CaCl}_{2} \cdot 2 \mathrm{H}_{2} \mathrm{O}$, citri acid, Fe-EDTA, $\mathrm{Na}_{2} \mathrm{CO}_{3}$, Trace metal mixed, and distilled water). They were maintained in the culture room for a month.

\section{Sample preparation}

All axenic cyanobacterial strains were grown in BG-11 medium for a month. The strains were harvested by filtering with 120 mesh cotton and washed with sterilized water. Biomass was freeze-dried. The dried masses were ground and extracted by maceration with $95 \%$ ethanol. The ethanolic extract were filtrated through Whatman No.1 filter paper and was concentrated to reduce the pressured rotary evaporator and to obtain the crude extracts. The potential ethanolic crude extracts were separated by liquid-liquid partition chromatography. The 3 different fractions, such as hexane, dichloromethane, and aqueous extracts were fractionated with varying polarity as presented in Figure 1. Initial separation of the crude extract was started between hexane and methanol at a ratio of $2: 1$. The hexane fraction was collected, while the methanol part was further separated between dichloromethane and distilled water at a ratio of $2: 1$. The 2 immiscible layers were dichloromethane and aqueous fractions. Each of the separated fractions from crude extracts was concentrated under vacuum at $40{ }^{\circ} \mathrm{C}$ and kept at $4{ }^{\circ} \mathrm{C}$ before it was used in the experiment. 
http://wjst.wu.ac.th

Dried masses of Nostoc species

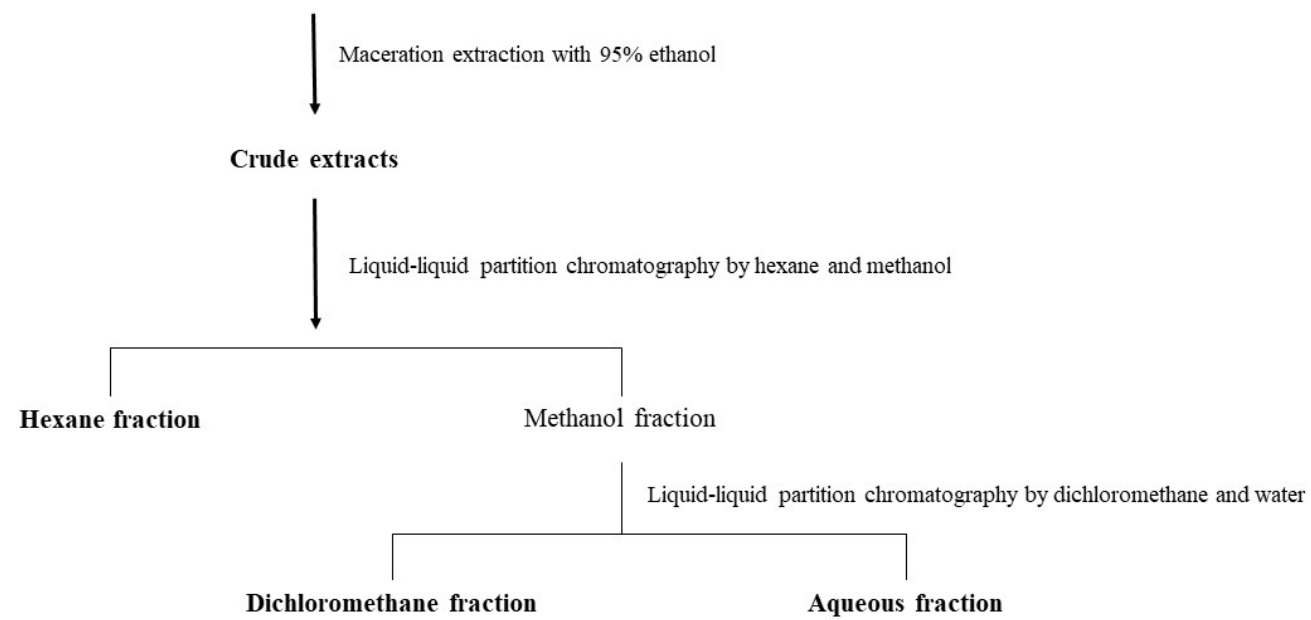

Figure 1 Extraction approaches of potential Nostoc samples using liquid-liquid partition chromatography.

\section{Cell culture}

MC3T3-E1 osteoblastic cell subclone 4 (ATCC ${ }^{\circledR}$ CRL-2593 ${ }^{\mathrm{TM}}$; passage 9 - 15) was cultured basal medium (BM), containing an $\alpha$-minimum essential medium (Gibco,USA), $10 \%$ fetal bovine serum (Biowest, USA ) and $1 \%$ penicillin/streptomycin antibiotic (biowest, USA ) in a humidified atmosphere of $5 \% \mathrm{CO}_{2}$ at $37{ }^{\circ} \mathrm{C}$. For the osteoblast cell differentiation assay, the cells were induced in differentiation media (DM), $4 \mathrm{mM} \beta$-glycerolphosphate (sigma-aldrich, USA), $1 \%$ penicillin/streptomycin antibiotic (Biowest, USA) and $50 \mu \mathrm{g} / \mathrm{mL}$-ascorbic acid (Sigma, Germany). For cell differentiation, MC3T3-E1 cells were seeded in a 12-well plate at a density of $2 \times 10^{4}$ cell/well. Cells were pre-cultured with the basal medium and incubated in a $5 \% \mathrm{CO}_{2}$ at $37^{\circ} \mathrm{C}$ for $24 \mathrm{~h}$. At $95 \%$ confluence, cells were induced by differentiation media (DM) with or without samples $(10 \mu \mathrm{g} / \mathrm{mL})$ and the medium was changed every 3 days.

\section{Cytotoxicity and cell proliferation (WST-1 assay)}

Cell viability was assessed using the WST-1 assay, which is a method for measuring metabolic activity and to incubate cells with a tetrazolium salt, such as MTT or WST-1. It was cleaved into a colored formazan product by metabolically active cells. The MC3T3-E1 cells were seeded in a 96-well plate (a density of $2 \times 10^{4}$ cell//well). Cells were treated with various concentrations of test samples (1$1,000 \mu \mathrm{g} / \mathrm{mL}$ ) and incubated in a $5 \% \mathrm{CO}_{2}$ at $37^{\circ} \mathrm{C}$ for 24 and $48 \mathrm{~h}$. After the incubation time, the cells were washed with PBS, followed by the addition of WST-1 solution $(1: 10, \mathrm{v} / \mathrm{v})$ and were incubated in a $5 \% \mathrm{CO}_{2}$ at $37{ }^{\circ} \mathrm{C}$ for $30 \mathrm{~min}$. The absorbance was measured on a microplate reader (Infinite pro2000, USA) at $450 \mathrm{~nm}$.

\section{Alkaline phosphatase (ALP) activity}

To determine alkaline phosphatase (ALP) activity, with slight modification from Pathomwichaiwat et al. [13], cells were maintained with DM for 9 days. They were washed by cold PBS twice and were lysed on ice for $30 \mathrm{~min}$. This was followed by sonication. The supernatants were obtained by centrifugation at $10,000 \mathrm{rpm}, 4{ }^{\circ} \mathrm{C}$ for $30 \mathrm{~min}$ and was preserved at $-20^{\circ} \mathrm{C}$ until use. The total protein content was analyzed using a Pierce ${ }^{\circledR}$ BCA protein assay kit. The ALP activity of the samples was determined by colorimetric assay using an alkaline phosphatase (Diethanolamine Detection Kit, Sigma 
http://wjst.wu.ac.th

Aldrich, USA). The ALP activity was calculated in ALP unit $/ \mathrm{mg}$ protein and expressed as $\%$ relative ALP activity compared with the control.

\section{Alizarin red S staining}

Alizarin Red S staining is the standard method to indicate and quantify matrix mineralization during the differentiation of osteoblast cultures. After cells were incubated with DM for 25 days, as described by Wang et al. [14] with a slight modification, cells were washed with cold PBS twice and fixed in absolute methanol at $4{ }^{\circ} \mathrm{C}$ for $30 \mathrm{~min}$. Cells were strained with $40 \mathrm{mM}$ Alizarine red for $15 \mathrm{~min}$, and observed under an invert microscope. Cells were rinsed with PBS, and then were dissolved with $10 \%$ cetylpyridinium chloride. They were incubated for $15 \mathrm{~min}$ before the measurement of the absorbance at $562 \mathrm{~nm}$. The mineralization was calculated and expressed in \% relative Ca deposition compared with the control.

\section{Phytochemical compounds screening}

All preliminary ethanolic crude extracts were screened by thin layer chromatography (TLC) techniques. The TLC protocol was developed with mobile phase systems of hexane and ethyl acetate (at a ratio of 7:3 (v/v). They were sprayed with an anisaldehyde $/ \mathrm{H}_{2} \mathrm{SO}_{4}$ reagent. TLC were visualized under a white light, UV $254 \mathrm{~nm}$ and UV $366 \mathrm{~nm}$ detectors, by using a TLC visualizer (CAMAG, Switzerland) and winCATS software.

\section{Statistical analysis}

The data were expressed as mean $\pm \mathrm{SD}$. Statistical comparisons between control and treatment groups were performed using software SPSS-version.23. Data were analyzed using One-way ANOVA analysis, with a value of $\mathrm{p}<0.05$ considered to be statically significant.

\section{Results and discussion}

Several studies have demonstrated that there are many natural products which have a stimulatory effect of the bone formation process, including proliferation and differentiation [5]. In order to reduce the risk of osteoporosis, which results from an imbalance in bone remodeling relative to bone formation and bone reabsorption among the ageing population, this present study evaluated Nostoc crude extracts on the efficacy of bone formation through proliferation, differentiation, and mineralization. The four Nostoc species were made axenic and cultured for a month, then extracted with $95 \%$ ethanol via maceration. The range of $\%$ yield crude extract was $7-10 \%(\mathrm{w} / \mathrm{w})$ and there was a variation between cyanobacterial species. All Nostoc extracts were screened for chemical compositions by TLC techniques. It was found that all extracts (lane no. 5 - 8) showed similar fingerprint patterns at different intensities of each band. After being sprayed with anisaldehyde $/ \mathrm{H}_{2} \mathrm{SO}_{4}$ reagent, it was observed that there were 2 bands which had the same $R_{f}$, which were $\beta$-carotene $\left(R_{f}=0.8\right)$ and chlorophyll a $\left(R_{f}=0.125-0.4\right)$, as shown in Figure 2. Moreover, other bands turned to violet, pink, dark blue or brick, positive results, which correspond with fatty acid, terpenoids, and steroid compounds. The results implied that the presence of carotenoids and chlorophyll a as pigment compounds which contain different intensities of each compound in extracts. $\beta$ carotene has been reported to represent $30 \%$ of total pigment in Nostoc sp. [15]. Four major carotenoids, including $\beta$-carotene, lycopene, lutein and zeaxanthine, were determined in Anabaena vaginicola and Nostoc calcicola from Northern Iran [12]. 

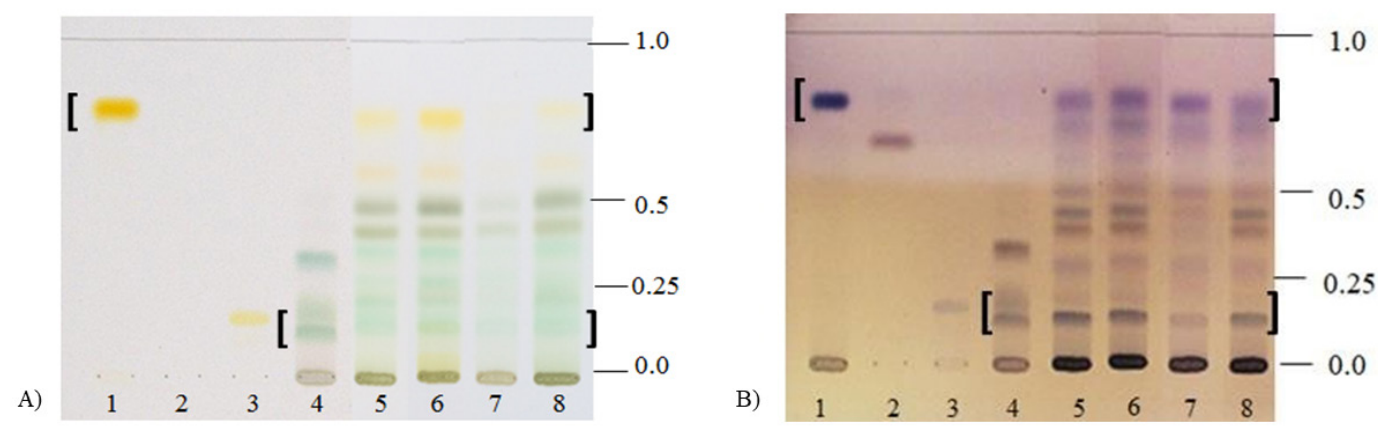

Figure 2(A-B) TLC chromatograms of 4 standards and 4 Nostoc extracts; stationary phase: silica gel aluminum sheet $60 \mathrm{~F}_{254}$; mobile phase: hexane: ethyl acetate (7: 3); white light detector (A) and sprayed with anisaldehyde $/ \mathrm{H}_{2} \mathrm{SO}_{4}$ detector(B); lane no. $1=\beta$-carotene, lane no. $2=\alpha$-tocopherol, lane no. $3=$ Xanthophyll, lane no. $4=$ Chlorophyll a, lane no. $=N$. parmelioides crude extract, lane no. $6=N$. punctiforme crude extract, lane no. $7=N$. muscorum crude extract, lane no. $8=N$. paludosum crude extract.

All crude extracts were analyzed for cytotoxicity and bone formation with osteoblast cell (MC3E1). $\beta$-carotene and genistein, which are osteogenesis stimulators, were used in all experiments, as a positive control. Considerably, the cell viability of $\beta$-carotene and genistein was more than $95 \%$, but did not significantly affect the cell proliferation when compared with the control $(100 \%)$. The previous studies suggested that a fixed concentration of $10 \mu \mathrm{M} \beta$-carotene exhibited bone differentiation but did not promote proliferation [16]. Likewise, it has been reported that genistein at a concentration of 0.01-1 $\mu \mathrm{M}$ can stimulate proliferation and differentiation [17]. As shown in Figure 3, the cell viability of the 4 Nostoc extracts at the various concentrations $(1-1,000 \mu \mathrm{g} / \mathrm{mL})$ were more than $80 \%$ as compared with the control, which did not differ among treatment groups after treatment for 24 and $48 \mathrm{~h}$. This suggests that all Nostoc extracts had no toxic effect on osteoblast cell. However, it did not significantly promote osteoblast cell proliferation. Furthermore, it has been reported that no signal of cytotoxicity of hexane, methanol, and water extract from Nostoc species at 24 h-exposure time was observed for the L929 cell by using MTT assay [18]. Moreover, extracts from Nostoc commune were not toxic to hepG2 cell, in vitro [19]. In addition, the potential cytotoxic effects of Nostoc microscopicum extracts which were investigated using various cell lines showed less cytotoxicity effect at concentrations of 50, 100, 200 and $400 \mu \mathrm{g} / \mathrm{mL}[20]$. 

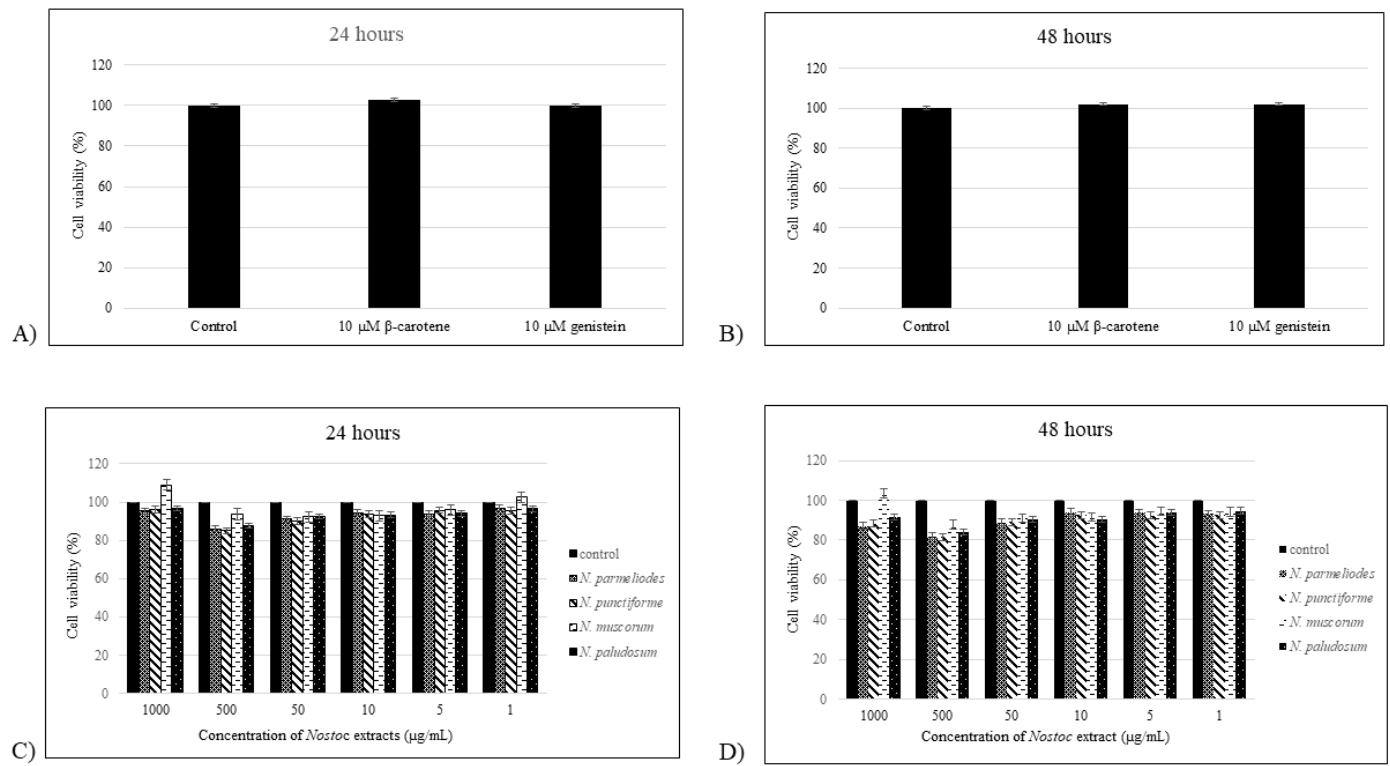

Figure 3 Effect of cytotoxicity and cell proliferation on osteoblast cell following treatment of 2 standards ( $\beta$-carotene and genistein) after being cultivated for 24 (A) and $48 \mathrm{~h} \mathrm{(B)} \mathrm{and} 4$ Nostoc extracts after being cultivated for 24 (C) and $48 \mathrm{~h}$ (D). Each value is mean \pm SD statistical analysis were performed using Duncan's multiple range test $(\mathrm{p}<0.05)$.

In general, osteogenesis or bone formation was divided into 3 processes continuously: proliferation, the increase of pre-osteroblast numbers ( 1 - 5 days); differentiation, the process by which a pre-osteoblast becomes a mature osteoblast ( 5 - 15 day); and mineralization, the formation of new bone matrices by mature osteoblast (25 - 30 days) [13]. At the end of the bone formation phase, osteoblasts can either become embedded in bone as osteocytes, become inactive osteoblasts or bone lining cells [21], or undergo programmed cell death (apoptosis) [21,22]. Under certain conditions, they may be able to differentiate into cells that produce chondroid bone [23], which is a dendritic structure that allows communications with other cells via gap junction as presented in Figure 4.

A)

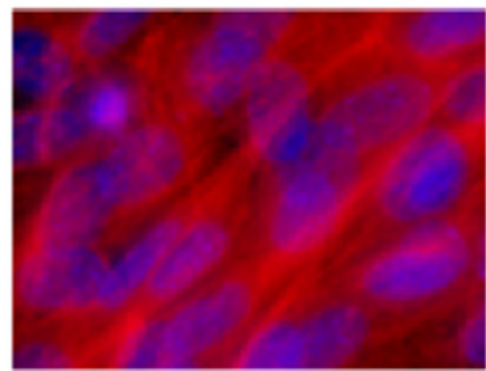

Osteoblast cell
B)

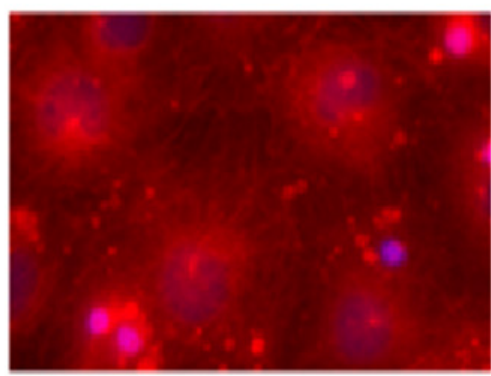

Osteocyte cell

Figure 4 Morphologic characteristics of osteoblast (MC3T3-E1) cells were detected under fluorescence microscopic by immunofluorescense straining after incubation for 9 days; cytoplasm cells were stained with tubulin (red) and the nuclei were stained with DAPI (blue). Osteoblasts grown in basal medium(A); Osteoblasts grown in an osteogenic medium, cells were surrounded with matrices and remained connected with each other as mature osteoblasts to become osteocytes (B). 
http://wjst.wu.ac.th

In order to see early osteoblast cell differentiation, we employed the activity of alkaline phosphatase (ALP), which is an osteoblast differentiation enzyme marker. As shown in Figure 5A, it was found that carotenoids, including $\beta$-carotene, xanthophyll, and chlorophyll a, showed increased ALP activity to $145.39 \pm 65.24,188.83 \pm 6.54$ and $183.71 \pm 3.4 \%$, respectively, while genistein did not show increasing ALP activity $(90.61 \pm 5.10 \%)$ when compared with the control. Among crude extracts, there were 3 Nostoc extracts, which are $N$. parmelioides $(195.18 \pm 127.81 \%)$, $N$ punctiforme $(134.12 \pm 50.08 \%$ ), and $N$. paludosum $(159.42 \pm 7.32 \%)$, that significantly increased in ALP activity at a fixed concentration of 10 $\mu \mathrm{g} / \mathrm{mL}$. Moreover, it was noticeable that the morphology of osteoblast changed to become osteocyte in samples, which resulted in higher ALP activity, as shown in the Figure 5B. Actually, during the bone formation process, osteoblast cells secreted transcription factors and families of growth factors, to form the osteoid and regulate the processes that initialize mineralization, whereas osteoblasts cells were surrounded with hard matrices and remained connected with each other as mature osteoblasts to become osteocytes [24]. For the last stage of bone formation, called extracellular matrix calcium deposits for mineralized nodule formation were stained with alizarine red S dye, which could be combined with calcium ions. The result showed that there were no differences in the calcium deposits among treatment groups at a concentration of $10 \mu \mathrm{g} / \mathrm{mL}$ after having been cultivated for 25 days, as presented in Figure 5C. These results suggest that a component of crude extracts from $N$. parmelioides, $N$ punctiforme, and $N$. paludosum stimulates osteoblast differentiation thorough ALP synthesis, but it has no effect on mineralization. These results are similar to the study by Cho et al. [25] which showed that red yeast rice powder can stimulate osteoblast cell differentiation by increasing ALP activity. However, it did not show any significant prominent extracellular matrix calcium deposit as measured by Alizarine red $\mathrm{S}$ and von Kossa staining after 15 days.
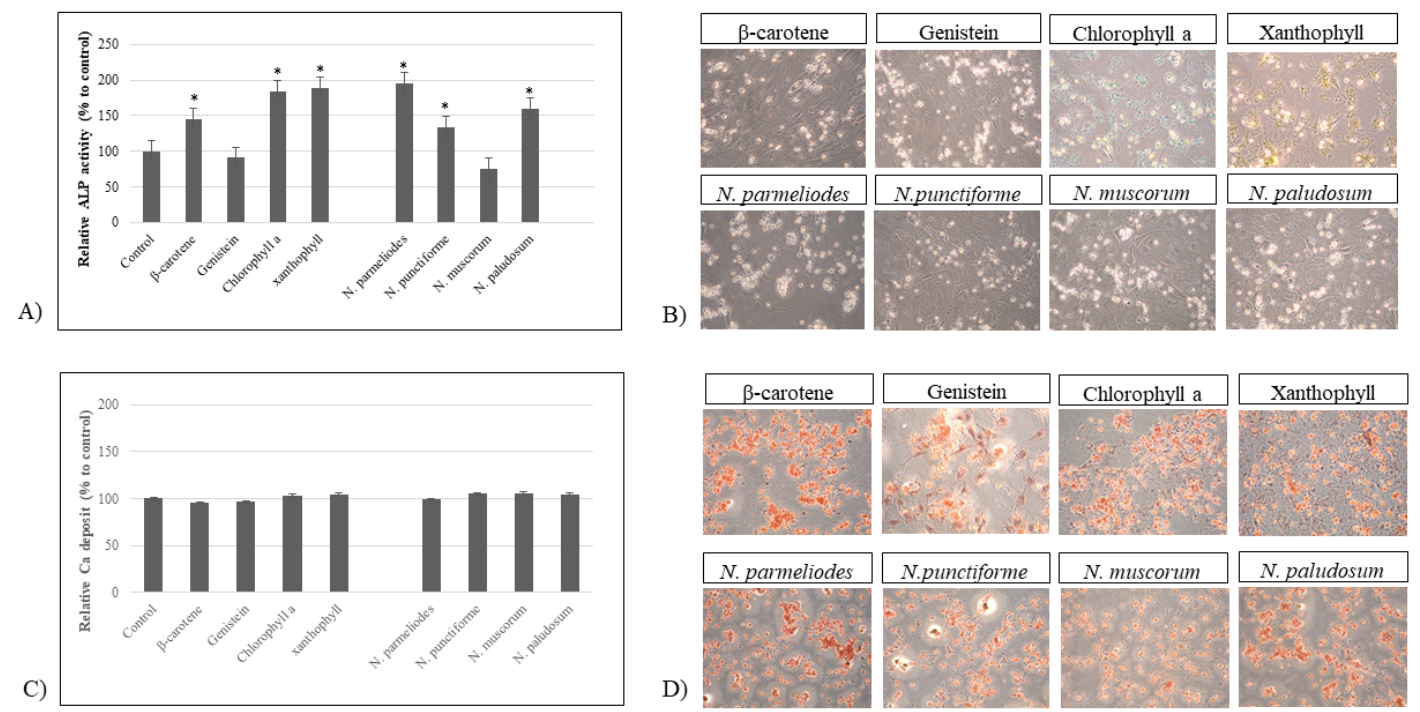

Figure 5 Effects of osteoblast differentiation following treatment of 4 standards ( $\beta$-carotene, genistein, chlorophyll a, and xanthophyll) and 4 Nostoc crude extracts ( $N$. parmelioides, $N$ punctiforme, $N$. muscorum and N. paludosum extracts); effect of alkaline phosphatase activity (A) with the morphology of differentiated osteoblast cell (B) after being induced for 9 days and $\mathrm{Ca}^{+}$deposition (C) and, the morphology of differentiated osteoblast cell (D) after being induced for 25 days. Each value is mean $\pm S D$, and statistical analysis were performed using Duncan's multiple range test $(\mathrm{p}<0.05)$. 
http://wjst.wu.ac.th

Because of their direct positive effects on osteoblast differentiation, 3 crude extracts from $N$. parmelioides, $N$ punctiforme, and $N$. paludosum which exhibited significant effects on ALP activity were further fractionated by liquid-liquid partition chormatography ( such as hexane, dichloromethane, and aqueous fractions) to determine the potential compounds. They were further analyzed for osteoblast differentiation with ALP assay. The ALP activity of hexane fraction from $N$. parmelioides, $N$ punctiforme, and $N$. paludosum were $181.72 \pm 6.756,194.34 \pm 2.36$ and $191.54 \pm 7.66 \%$, respectively (Figure 6). However, the aqueous fractions showed significantly less ALP activity than hexane and dichloromethane fractions. Considering TLC chromatogram (Figure 7), N. parmelioides, N punctiforme, and $N$. paludosum extracts showed similar TLC patterns, which contained chemical constituents, espectially in hexane and dichloromethane fractions. It can be noticed that those with more intensity of chemical constituents exhibited higher ALP activity. The results might be due to a potential major compound in nonpolar solvent as represented in the TLC fingerprint, which corresponds to carotenoids ( $\beta$-carotene and chlorophyll a). It has been reported also that carotenoids, which are $\beta$-cryptoxanthin, promote the proliferation of osteoblastic cells [26] and can increase the expression of Runx2, ALP, and collagen I type mRNA in MC3T3-E1 cells [27]. Moreover, the study of the combined effect of isoflavone and carotenoids showed higher ALP activity than the individual treatment with each [14].

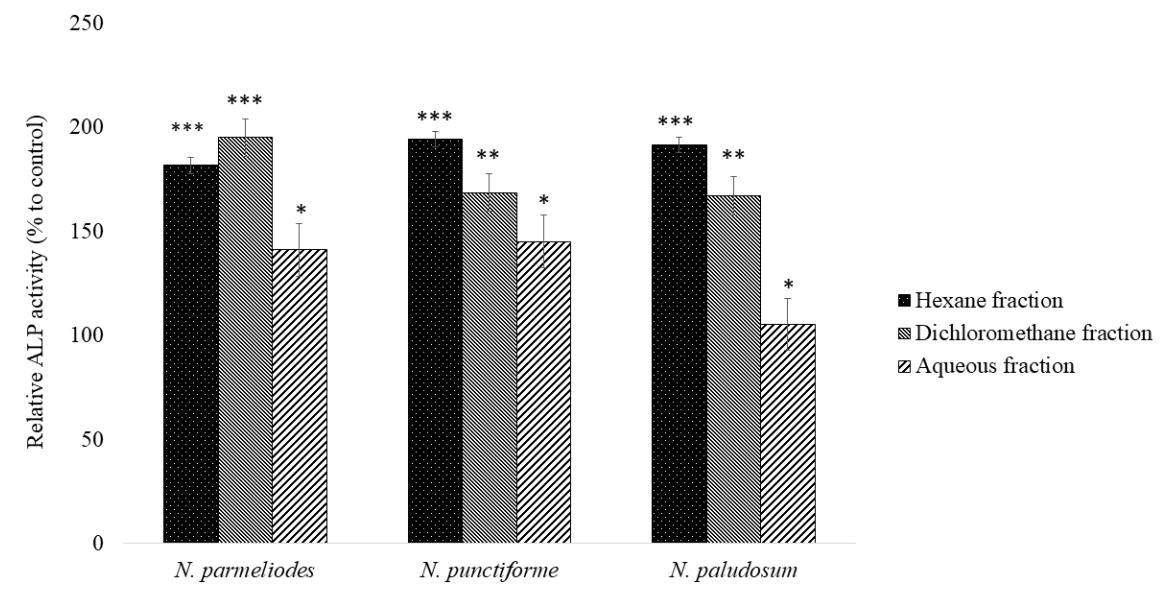

Figure 6 Effect of ALP activity on osteoblast cells following treatment of 3 different fractions from potential crude extracts ( $N$. parmelioides, $N$ punctiforme, and $N$. paludosum extracts) at a concentration of $10 \mu \mathrm{g} / \mathrm{mL}$ after inducing differentiation for 9 days. Each value is mean $\pm \mathrm{SD}$, and statistical analysis were performed using Duncan's multiple range test $(\mathrm{p}<0.05)$. 


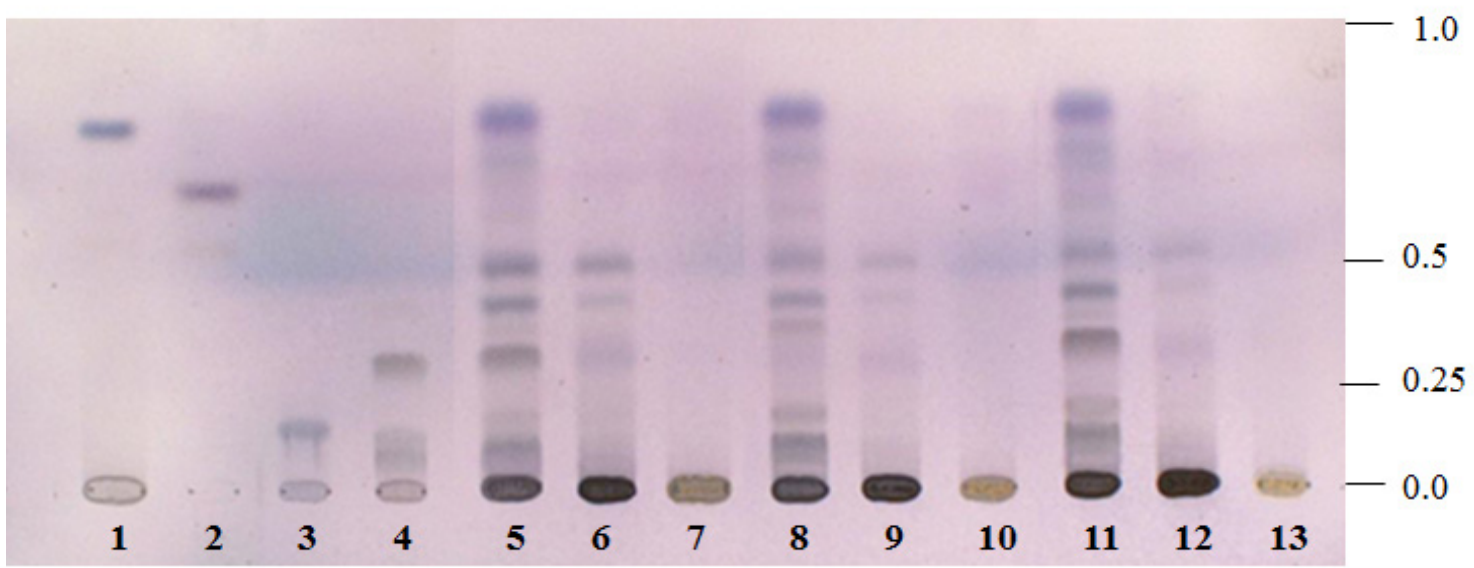

Figure 7 TLC chromatograms of carotenoids, $\alpha$-tocopherol and 9 partitional extracts; stationary phase: silica gel aluminum sheet $60 \mathrm{~F}_{254}$; mobile phase: hexane: ethyl acetate (7: 3); white light sprayed with anisaldehyde $/ \mathrm{H}_{2} \mathrm{SO}_{4}$ detector; lane no. $1=\beta$-carotene, lane no. $2=\alpha$-tocopherol, lane no. $3=$ Xanthophyll, lane no. $4=$ Chlorophyll a, lane no. $=N$. parmelioides hexane fraction, lane no. $6=N$. parmelioides dichloromethane fraction, lane no.7 $=N$. parmelioides aqueous fraction, lane no. $8=N$. punctiforme hexane fraction, lane no. $9=N$. punctiforme dichloromethane fraction, lane no.10 $=N$. punctiforme aqueous fraction, lane no.11 $=N$. paludosum hexane fraction, lane no.12 $=N$. paludosum dichloromethane fraction, lane no. $13=N$. paludosum aqueous fraction.

\section{Conclusions}

This study has suggested that all crude extracts from N. muscorum, N. parmelioides, N punctiforme, and $N$. paludosum show no significant cytotoxic effect on osteoblast cells (MC3T3-E1). The crude extracts of 3 Nostoc species, which are $N$. parmelioides, $N$ punctiforme, and $N$. paludosum, exhibited direct positive effects on osteoblast differentiation in the formation of osteocytes by increasing alkaline phosphatase (ALP). Such a formation has an important role in osteoblast differentiation. Further findings demonstrated that major potential compounds, which stimulated osteoblast differentiation, are contained in nonpolar extract, which might correspond with carotenoids ( $\beta$-carotene, xanthophyll and chlorophyll a). This suggests that Nostoc extract can be a beneficial nutrient as an alternative, natural source of treatment for osteoporosis.

\section{Acknowledgements}

This research was funded by the Partnership Program in Promotion of Graduates in Master's Degree and Doctoral Degree between the Thailand Institute of Scientific and Technological Research (TISTR) and Educational institutions. All Nostoc species were facilitated by the Algal Expert Centre, TISTR. All laboratory was facilitated by Innovative Herbal Products TISTR and Faculty of Pharmacy, Mahidol University, Thailand. 
http://wjst.wu.ac.th

\section{References}

[1] World Health Organization. WHO Scientific Group on the Assessment of Osteoporosis at Primary Health Care Level. Brussels, Belgium, 2004.

[2] S Ozgocmen, H Kaya, E Fadillioglu, R Aydogan and Z Yilmazb. Role of antioxidant systems, lipid peroxidation, and nitric oxide in postmenopausal osteoporosis. Mol. Cell. Biochem. 2007; 295, 4552.

[3] C Aparicio and MP Ginebra. In Biomineralization and Biomaterials. Woodhead Publishing, England, 2015, p. 129-46.

[4] X Zeng, J Tian, L Cui, Y Wang, Y Su, X Zhou and X He. The phenolics from the roots of Livistona chinensis show antioxidative and obsteoblast differentiation promoting activity. Molecules 2014; 19, 263.

[5] JT Woo, T Yonezawa and K Nagai. Phytochemicals that stimulate osteoblastic differentiation and bone formation. J. Oral Biosci. 2010; 52, 15-21.

[6] MGD Morais, BDS Vaz, EGD Morais and JAV Costa. Biologically active metabolites synthesized by microalgae. Bio. Med. Res. Int. 2015; 2015, 8357-61.

[7] WDP Stewart. Some of aspects of structure and function in N2-fixinng cyanobacteria. Annu. Rev. Microbiol. 1980; 34, 497-536.

[8] SSM Zeeshan, D Biswas, A Farooqui and MJ Arif. Screening of selected cyanobacterial strains for phytochemical compounds and biological activities in vitro. Biochem. Cell. Arch. 2010; 10, 163-8.

[9] MSA Hameed, SH Hassan, R Mohammed and R Gamal. Isolation and characteriazation of antimicrobial active compounds from the cyanobacterium Nostoc commune Vauch. J. Pure Appl. Microbiol. 2013; 7, 109-16.

[10] M Ninomiya, H Satoh, Y Yamaguchi, H Takenaka and M Koketsu. Antioxidative activity and chemical constituents of edible terrestrial alga Nostoc commune Vauch. Biosci. Biotechnol. Biochem. 2011; 75, 2175-7.

[11] SA Agger, F Lopez-Gallego, TR Hoye and C Schmidt-Dannert. Identification of sesquiterpene synthases from Nostoc punctiforme PCC 73102 and Nostoc sp. strain PCC 7120. J. Bacteriol. 2008; 190, 6084-96.

[12] MS Hashtroudi, Z Shariatmadari, H Riahi and A Ghassempour. Analysis of Anabaena vaginicola and Nostoc calcicola from Northern Iran, as rich sources of major carotenoids. Food Chem. 2013; 136, 1148-53.

[13] T Pathomwichaiwat, P Ochareon, N Soonthornchareonnon, Z Ali, I A Khan and S Prathanturarug. Alkaline phosphatase activity-guided isolation of active compounds and new dammarane-type triterpenes from Cissus quadrangularis hexane extract. J. Ethnopharmacol. 2015; 160, 52-60.

[14] N Wang, X Wang, W Cheng, H Cao, P Zhang and L Qin. Puerarin promotes osteogenesis and inhibits adipogenesis in vitro. Chin. Med.J. 2013; 8, 1-17.

[15] T W Goodwin. The natural and distribution of carotenoids in some blue-green algae. J. Gen. Microbial. 1957; 17, 467-73.

[16] Y Nishide, Y Tousen, M Tadaishi, M Inada, C Miyaura, MC Kruger and Y Ishimi. Combined Effects of soy isoflavones and beta-carotene on osteoblast differentiation. Int. J. Environ. Res. Publ. Health. 2015; 12, 13750-61.

[17] J Dai, Y Li, H Zhou, J Chen, M Chen and Z Xiao. Genistein promotion of osteogenic differentiation through BMP2/SMAD5/RUNX2 signaling. Int. J. Biol. Sci. 2013; 9, 1089-98.

[18] VR Lopes, M Schmidtke, MH Fernandes, R Martins and V Vasconcelos. Cytotoxicity in L929 fibroblasts and inhibition of herpes simplex virus type 1 Kupka by estuarine cyanobacteria extracts. Toxicol. In Vitro 2011; 25, 944-50.

[19] Y Yang, Y Park, DA Cassada, DD Snow, DG Rogers and J Lee. In vitro and in vivo safety assessment of edible blue-green algae, Nostoc commune var. sphaeroides Kutzing and Spirulina plantensis. Food Chem. Toxicol. 2011; 49, 1560-4. 
http://wjst.wu.ac.th

[20] T Batsalova, D Moten, D Basheva, I teneva and B Dzhamazov. In vitro cytotoxicity and antioxidative potential of Nostoc Microscopicum (Nostocales, Cyanobacteria). Toxicol. Forensic Med. 2016; 1, 9-17.

[21] SC Manolagas. Birth and death of bone cells: Basic regulatory mechanisms and implications for the pathogenesis and treatment of osteoporosis. Endocr. Rev. 2000; 21, 115-37.

[22] RL Jilka, RS Weinstein, T Bellido, AM Parfitt and SC Manolagas. Osteoblast programmed cell death (apoptosis): Modulation by growth factors and cytokines. J. Bone. Miner. Res. 1998; 13, 793802.

[23] M Li, N Amizuka, K Oda, K Tokunaga, T Ito, K Takeuchi, R Takegi and T Maeda. Histochemical evidence of the initial chondrogenesis and osteogenesis in the periosteum of a rib fracture model: implications of osteocyte involvement in periosteal chondrogenesis. Microsc. Res. Tech. 2004; 64, 330-42.

[24] X Zeng, J Tian, K Cai, X Wu, Y Wang, Y Zheng, Y Su and L Cui. Promoting osteoblast differentiation by the flavanes from Huanghan Maofeng tea is linked to a reduction of oxidative stress. Phytomedicine 2014; 21, 217-24.

[25] YE Cho, E Alcantara, S Kumaran, KH Son, HY Sohn and JH Lee. Red yeast rice stimulates osteoblast proliferation and increase alkaline phosphatase activity in MC3T3-E1 cells. Nutr. Res. 2010; 30, 501-10.

[26] S Uchiyama and M Yamaguchi. $\beta$-cryptoxantin stimulates cell proliferation and transcriptional activity in osteoblastic MC3T3-E1 cells. Int. J. Mol. Med. 2005; 15, 675-81.

[27] S Uchiyama and M Yamaguchi. $\beta$-cryptoxantin stimulated cell differentiation and mineralization in osteoblastic MC3T3-E1 cells. J. Cell. Biochem. 2005; 95, 1224-34. 